\title{
HIDROTEHNIČKI I GEOTEHNIČKI UZROCI SLIJEGANJA OBJEKTA MUZIČKE ŠKOLE U TUZLI
}

\author{
Nedim Suljić ${ }^{1}$ \\ Zahid Bašić ${ }^{2}$
}

UDK: 624.131.542(497.6TUZLA)

DOI:10.14415/konferencijaGFS 2016.065

Rezime: Objekat Muzičke škole u Tuzli je oblika isječka kružnog prstena podijeljenog na pet dijelova. Spratnost je podrum, prizemlje i sprat. Objekat je izgrađen sredinom 50-tih godina prošlog vijeka. U neposrednoj blizini predmetnog objekta nalaze se izgrađena tri panonska jezera, a sa sjeverne strane je Trnovačka padina sa neriješenom odvodnjom oborinskih voda kao i nizom neplanski izgrađenih stambenih individualnih objekata.

Na ovom lokalitetu su najveća slijeganja terena na području grada Tuzle, a posljedice slijeganja terena su uglavnom izražene u nagnutosti objekta Muzičke škole ka sjevernoj strani, a manje u deformacijama odnosno pukotinama na nosivim konstruktivnim elementima. Značajan uticaj na prekomjerno slijeganje i nagnutost objekta Muzičke škole učinila je i eksploatacija kamene soli. Takođe, uticaj dugotrajnih padavina uz nepostojanje oborinske kanalizacije na predmetnom području se odražava i na objekat Muzičke škole. Tokom perioda majskih poplava 2014. godine kada je područje sjeverne gradske saobraćajnice od muzičke škole do pravoslavne crkve bilo potpuno potopljeno, predstavlja bitan pokazatelj negativnog uticaja infiltracije oborinskih voda $u$ tlo $i$ oticanja tih voda slivom kojem pripada objekat Muzičke škole, što čini bitan faktor mogucih deformacija i terena i predmetnog objekta.

Ključne riječi: padavine, slijeganje, eksploatacija soli, oborinska kanalizacija.

\section{UVOD}

Objekat muzičke škole u Tuzli je izgrađen 1956. godine. Tlocrt objekta je u obliku isječka kružnog prstena podijeljenog na pet dijelova širine od po $9^{\circ}$ gdje su smješteni nosivi stubovi. Dužina manjeg luka na južnoj strani, gdje se nalazi glavni ulaz, iznosi $20,74 \mathrm{~m}$, dok je dužina većeg luka sa sjeverne strane 35,26 m. Bočne strane objekta na istočnoj i zapadnoj strani su dužine po $16,65 \mathrm{~m}$. Objekat je spratnosti podrum, prizemlje i sprat. Glavni ulaz u objekat je preko dvokrilnih vrata (južna strana objekta), a ispred glavnog ulaza odnosno sa južne strane po cijeloj širini objekta proteže se lučni natkriveni prostor širine 2,60 m koji je oslonjen na šest stubova okruglog poprečnog presjeka, prečnika $40 \mathrm{~cm}$. Ulaz u objekat čini vjetrobran na kome se nalaze tri stepenika, a na ovaj

\footnotetext{
${ }^{1}$ Prof.dr.sc. Nedim Suljić, Univerzitet u Tuzli, Rudarsko-geološko-građevinski fakultet, Univerzitetska 2, Tuzla, Bosna i Hercegovina, tel. 0038735320 550, e - mail: nedim.suljic@untz.ba

${ }^{2}$ Prof.dr.sc. Zahid Bašić, Univerzitet u Tuzli, Rudarsko-geološko-građevinski fakultet, Univerzitetska 2, Tuzla, Bosna i Hercegovina, tel. 0038735320550.
} 
Contemporary achievements in civil engineering 22. April 2016. Subotica, SERBIA

prostor se nadovezuje foaje u kome je smješteno stepenište na sjevernoj strani objekta. Stepenište vodi u podrum i na sprat objekta. Sa zapadne i istočne strane foajea, odnosno u središnjem dijelu prizemlja protežu se lučni holovi. U konstruktivnom pogledu predmetni objekat je izgrađen od armiranog betona i sa zidanim nosivim zidovima od pune opeke, sistemom linearnih i lučnih armirano betonskih greda i armirano betonskih stubova.

Objekat muzičke škole je izgrađen na terenu na kome je slijeganje postajalo još prije gradnje predmetnog objekta (period mjerenja slijeganja od 1914. - 1956. godine). Godine 1914. snimljena su slijeganja terena veća od 1,0 metar na lokalitetu gdje je izgrađena muzička škola 1956. godine.

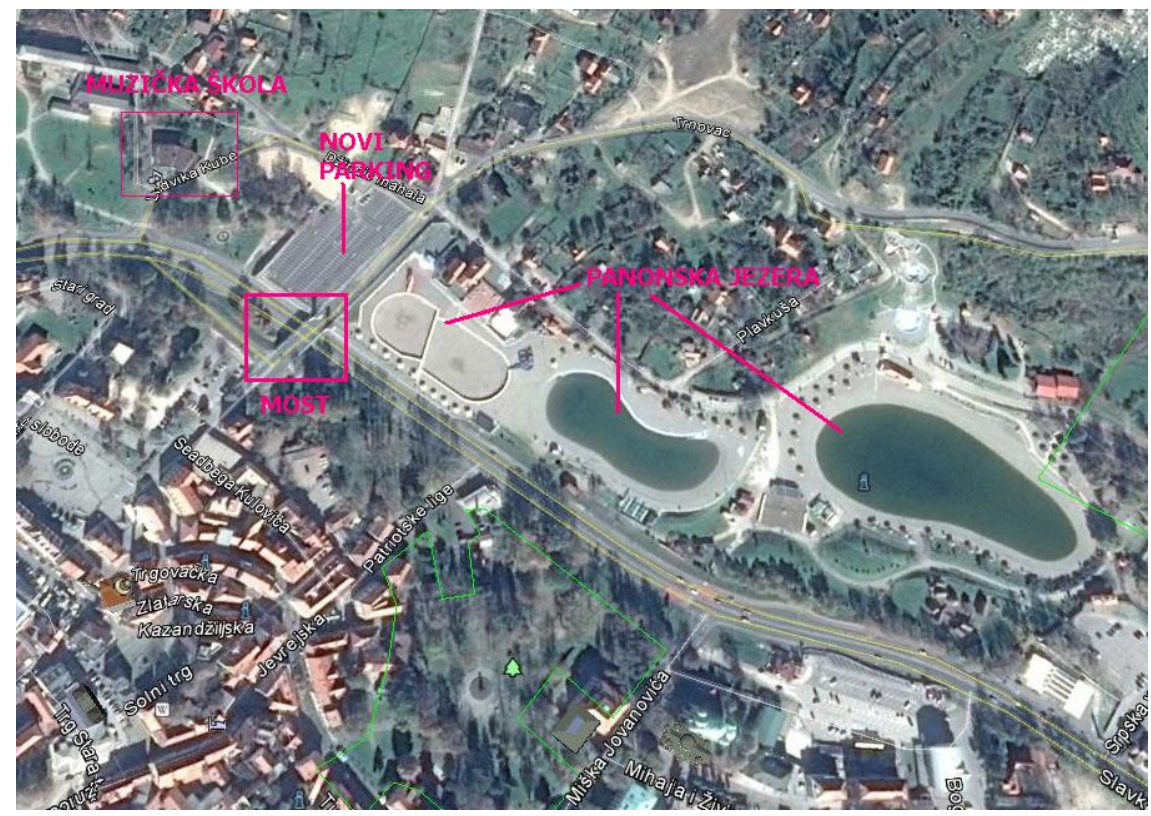

Slika 1.Položaj muzičke škole

U neposrednoj blizini objekta muzičke škole izgrađena su tri panonska jezera (prvo jezero 2003. godine, drugo 2009. godine i treće jezero izgrađeno 2012. godine i koje se nalazi oko $160 \mathrm{~m}$ od muzičke škole). Iste 2012. godine je izgrađen i most na udaljenosti oko 130 m koji spaja gradsku saobraćajnicu sa putem ka Univerzitetsko kliničkom centru kao i novi asfaltirani parking prostor kapaciteta oko 250 parking mjesta koji je udaljen od muzičke škole 80 metara. Ovo su dodatna opterećenja koja utiču na deformacije i slijeganje odranije nestabilnog terena na lokaciji muzičke škole [1].

U radu se analizira uticaj eksploatacije kamene soli na slijeganje područja gdje se nalazi muzička škola, te uticaj neriješene odvodnje oborinskih voda sa padine iznad muzičke škole kao i nedavna izgradnja trećeg panonskog jezera, armirano betonskog mosta, asfaltiranog parking prostora kao i armirano betonske gabionske konstrukcije dužine 60 $\mathrm{m}$ u neposrednoj blizini škole, na terenu gdje je godinama izraženo znatno slijeganje terena. 


\section{DEFORMACIJE I OŠTEĆENJA NA OBJEKTU}

Prema vidljivim pukotina na nosivim elementima konstrukcije objekta može se smatrati da objekat muzićke škole nije teže konstruktivno oštećen te da pripada grupi srednje do teže oštećenih objekata. Uočljivo je da je objekat nagnut u poprečnoj osi u pravcu jugjugoistok.

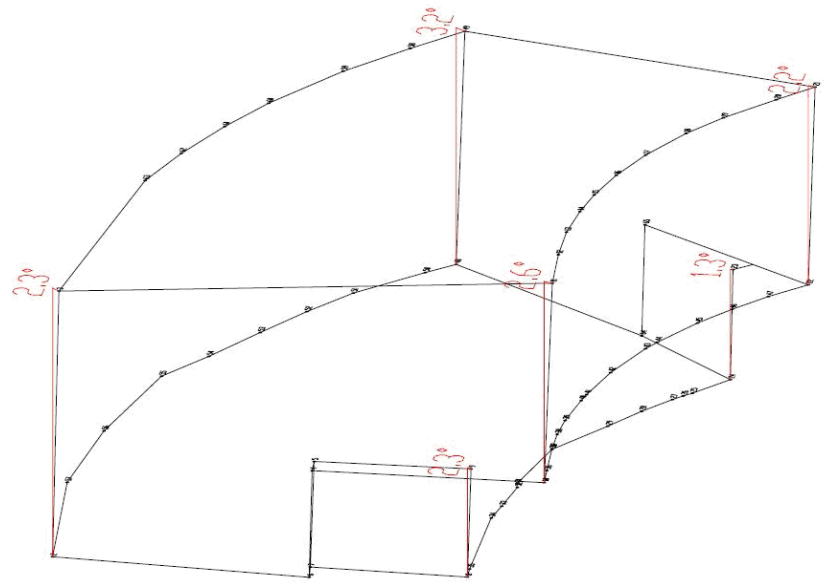

Slika 2.Horizontalne deformacije objekta

Objekat muzičke škole je rješenjem građevinsko-urbanističke inspekcije napušten sredinom 2012. godine. Današnjim vizuelnim pregledom objekta vidljiva je denivelacija i vertikalni otklon prema ulazu u objekat. Iz tog razloga, tokom decembra 2015. godine, izvršeno je geodetsko snimanje vidljivih odstupanja koja su prikazana na slici 3, gdje su izmjerene vrijednosti otklona u stepenima u iznosima $2,3^{\circ}, 3,2^{\circ}, 2,6^{\circ}, 2,2^{\circ}, 1,3^{\circ}, 2,3^{\circ}$. Posljedice slijeganja terena su uglavnom izražene u nagnutosti objekta, a manje $u$ deformacijama, odnosno prekomjernim pukotinama na nosivim konstruktivnim elementima [1]. Nakon napuštanja objekta isti nije konzerviran niti na bilo koji način zaštićen od uticaja atmosferilija, a prije svega od uticaja padavina. Na sjevernoj strani objekta sve padavine se slijevaju niz sjevernu fasadu, a horizontalni i vertikalni olučni kanali nisu u funkciji, jer su oštećeni usljed dotrajalosti i neodržavanja. Dalje, kiše koje se slijevaju niz sjevernu fasadu direktnu se infiltriraju u tlo ispod objekta i u sam objekat (njegov podrumski dio). Takođe, ni prozorski otvori nisu uopšte zaštićeni od prodora kiše u unutrašnjost objekta, a vidljivi su samo ostaci starog najlona koji je vjerovatno ostao još od 2012. godine, odnosno nakon napuštanja objekta. Zbog direktnog prodora kiše u unutrašnjost podrumskih, prizemnih i spratnih prostorija, uočene su deformacije na podovima pojedinih prostorija u vidu izdizanja parketa od uticaja prekomjerne vlage, kao i oštećenja zidova i stropova objekta od prodora kiše [1].

Oborinske vode sa padine na sjevernoj strani se nekontrolisano slijevaju i dodatno duži niz godina podlokavaju objekat muzičke škole. Ovo je naročito izraženo nakon padavina dužeg vremena trajanja kada se padina, odnosno zelena površina sa sjeverne strane potpuno zasiti vlagom, te nakon toga sve bruto padavine na podslivu sa sjeverne strane objekta postaju i efektivne padavine i direktan oticaj (površinski i podpovršinski), što 
Contemporary achievements in civil engineering 22. April 2016. Subotica, SERBIA

bez postojanja oborinske kanalizacije i drenažnog sistema direktno utiče na stabilnost i mogućnost nejednolikog slijeganja objekta muzičke škole usljed podlokavanja temeljne konstrukcije i kvašenja tla ispod temelja objekta. Uticaj prekomjernih padavina uz nepostojanje oborinske kanalizacije na predmetnom području se odražava i na objekat muzičke škole, te se može zaključiti da tokom perioda majskih poplava 2014. godine kada je područje sjeverne gradske saobraćajnice od predmetnog objekta do pravoslavne crkve bilo potpuno potopljeno, što je značajan pokazatelj negativnog uticaja infiltracije oborinskih voda u tlo kao i površinskog oticaja tih voda slivom, što uz nepostojanje adekvatne kanalizacione mreže čini bitan činilac mogućih deformacija i terena i predmetnog objekta.

Na užem lokalitetu objekta muzičke škole, 2012. godine, izvršena je gradnja trećeg panonskog jezera sa izradom nasipa visine $4,0 \mathrm{~m}$ do 6,0 $\mathrm{m}$ koji služi kao njegov oslonac ili direktna podloga. Prilikom gradnje nasipa vršeno je zbijanje slojeva ugrađenog zemljanog materijala do potrebnog modula stišljivosti. Izgradnjom trećeg panonskog jezera na specifičnim geološkim uslovima terena, dodatno je opterećen prostor pored lokaliteta Muzičke škole, a naročito u ljetnim danima kada pored maksimalne zapremine vode u jezeru imamo i dinamičko opterećenje od brojnih kupača. Dalje, za zaštitu stabilnosti kosine navedenog nasipa izgrađena je potporna konstrukcija od armirano betonskih gabionskih korpi u dužini oko $50,0 \mathrm{~m}$ i visine od 3,0 do $5,0 \mathrm{~m}$. Ovo predstavlja značajno linijsko opterećenje na terenu koji je podložan slijeganju još od 1914. godine kada su i izvršena prva geodetska mjerenja veličina slijeganja na ovom području. Poseban uticaj na oštećenja i deformaciju objekta muzičke škole ima i izgrađeni nadvožnjak, koji je fundiran na temeljnim armirano betonskim stopama. Armirano betonska stopa nadvožnjaka (oslonac) na južnoj strani je fundirana u laporce na dubini 3,6 m sa nivoom podzemne vode od 3,0 m od površine terena, a oslonac nadvožnjaka na sjevernoj strani se trebao fundirati u laporcima koji su na dubini 2,3 m sa nivoom podzemne vode od $0,9 \mathrm{~m}$ mjereno od površine terena [4].

\section{SLIJEGANJE TERENA NA LOKALITETU KOD MUZIČKE ŠKOLE}

Opšti problem deformacija terena u Tuzli, nastao je kao posljedica nekontrolisanog izlučivanja slane vode, star je koliko i eksploatacija solnog ležišta, ali su posljedice ove eksploatacije uočene znatno kasnije, a uzroci deformacija terena definitivno utvrđeni tek 1954. godine. Dugogodišnja eksploatacija soli na području grada Tuzle imala je za posljedicu slijeganje u središnjem dijelu grada uzrokujući značajne štete na infrastrukturi i objektima. Kontrola deformacije terena na području eksploatacije Tuzlanskog sonog ležišta se vrši kontinuirano od 1956. godine. Najveća slijeganja tla zabilježena su u periodu 1947. do 1991. gdje je u središnjem dijelu grada registrirano slijeganje više od $12 \mathrm{~m}$. Maksimalno slijeganje u toku jedne godine zabilježeno je 1979. godine i iznosilo je $745 \mathrm{~mm}$, te 1983. godine kada je iznosilo $1100 \mathrm{~mm}$. Nakon navedenih devastacija terena započinje proces obustave eksploatacije te potpuno obustavljanje crpljenja na solnim bunarima je nastupilo 29.05.2007. godine od kada se vrši kontinuiran i kompleksan monitoring. Istovremeno, proizvodnja soli se obavlja na ležištu Tetima zadovoljavajući potrebe hemijske industrije. 

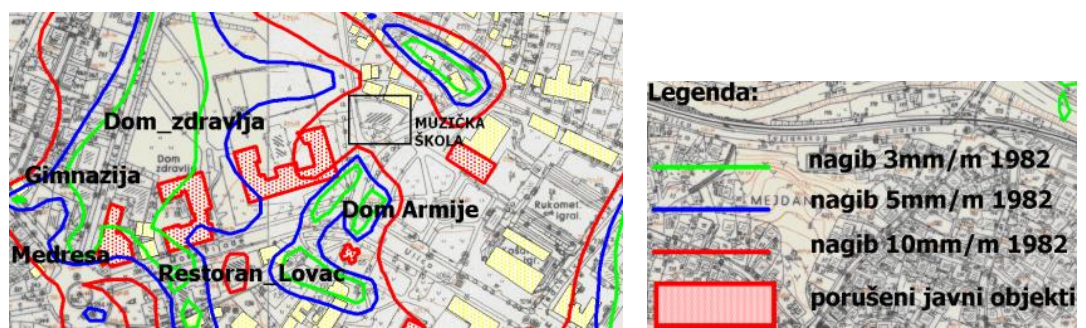

Slika 3. Slijeganje terena za 1982. godinu

Sa slika 3 i 4 vidi se da je lokacija muzičke škole imala nagib terena od $10 \mathrm{~mm} / \mathrm{m}$ tokom 1982. i 1991. godine, što je bila posljedica uglavnom eksploatacije soli iz solnih bunara na Trnovačkoj padini iznad predmetnog objekta [3].
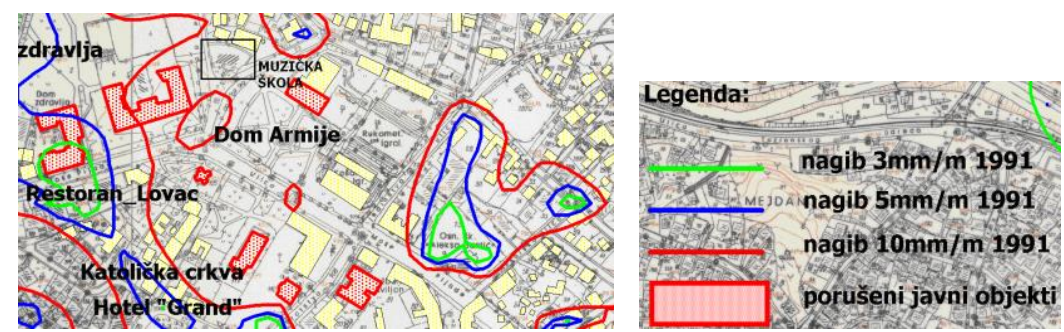

Slika 4. Slijeganje terena za 1991. godinu

Od zaustavljanja eksploatacije crpljenja na solnim bunarima u maju 2007. godine do danas, došlo je do smanjene destrukcije površine terena, a samim tim i do smanjene ugroženosti objekata $\mathrm{i}$ infrastrukture u užem dijelu gradskog područja u odnosu na razdoblje intenzivne eksploatacije slanice.
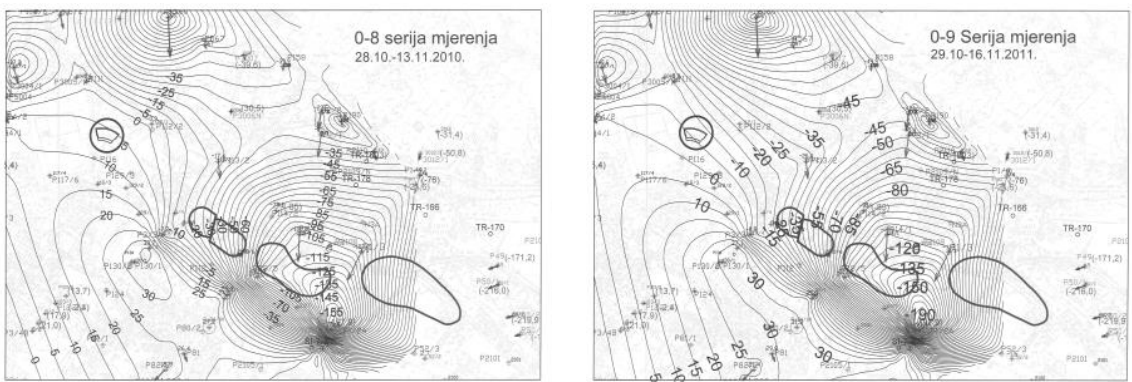

Slika 5. Deformacije terena kod muzičke škole nakon zatvaranja solnih bunara

U periodu od 2007. do 2009. godine dolazi do prelaza iz procesa slijeganja u proces izdizanja što je logička posljedica promjena zavodnjenosti masiva [2]. U periodu 2007. do 2008. godina oko 50,5 \% mjernih tačaka se izdiže, a u razdoblju od 2008. do 2009. 
Contemporary achievements in civil engineering 22. April 2016. Subotica, SERBIA

oko $88 \%$ mjernih tačaka, da bi zatim uslijedilo smirivanje i nastavak minimalnog slijeganja [2].

\section{ZAKLJUČNA RAZMATRANJA}

Objekat muzičke škole je izgrađen na terenu podložnom prekomjernom slijeganju koje datira još od 1914. godine. Značajan uticaj na proces slijeganja muzičke škole kao i okolnog terena imala je eksploatacija slanice iz solnih bunara. Takođe, padina terena iznad muzičke škole je sa neriješenom odvodnjom oborinskih voda, nepostojanje kanalizacione mreže, te značajna zavodnjenost padine iza predmetnog objekta, utiču na znatnu infiltraciju što uz nepostojanje drenaže iza objekta doprinosi podlokavanju temelja i mogućnosti njifovog nejednolikog slijeganja. Određeni uticaj deformaciji objekta ima i izgrađeno treće panonsko jezero, armirano betonski most kao i gabionska konstrukcija od armirano betonskih korpi, što predstavlja novo dodatno opterećenje na teren pored muzičke škole. Zatvaranjem solnih bunara 2009. godine dolazi do smanjenja slijeganja terena i do vremenskog izdizanja pojedinih mjernih tačaka, što predstavlja postepeno smirivanje terena. Neophodno je riješiti oborinsku kanalizaciju na Trnovačkoj padini iza objekta muzičke škole, izvesti drenažni sistem iza objekta čime će se onemogućiti mogućnost novih slijeganja objekta muzičke škole u Tuzli.

\section{LITERATURA}

[1] Suljić N., Bašić Z.: Nalaz vještačenja uzroka slijeganja objekta muzičke škole u Tuzli, 2015.

[2] Taletović N, Isabegović J, Avdić A, Šabović A.: Rezultati geodetskih osmatranja karakteristične zone slijeganja na solnom ležištu u Tuzli analiziranih kroz $3 D$ modele u posteksploatacijskom razdoblju, Zbornik građevinskog fakulteta Sveučilišta u Mostaru, 2014.

[3] Kikanović N.: Uticaj slijeganja na urbani razvoj i ranjivost prostora kao determinante razvoja, magistarski rad, Univerzitet u Tuzli, 2010.

[4] Suljić N., Kikanović N.: The Basis of the Spatial Development of the System of Settlements on the Example of Municipalities Tuzla, Scientific professional society for environmental protection of Serbia - ECOLOGICA, Belgrade, Serbia, UDC:502.33:711.28(497.15), No 76, 2014.

\section{HYDROTECHNICAL AND GEOTECHNICAL CAUSES SUBSIDENCE MUSIC SCHOOL IN TUZLA}

Summary: The building of the Music School in Tuzla is a form snippet circular ring divided in five parts. The building was built in the mid-50s of the last century. In the immediate vicinity of the building are constructed three Pannonian lakeand on the north 
Савремена достигнућа у грађевинарству 22. април 2016. Суботица, СРБИЈА

side of the Trnovačka slopes with unresolved drainage of precipitation water as well as a series of unplanned built residential individual buildings.

On this locality are largest subsidence in the city of Tuzla, and the consequences of subsidence are mainly expressed in skewed the building of the Music School to the north side, and less deformation or cracks in the supporting structural elements.

A significant influence on excessive subsidence and tilt of object Music School has made the exploitation of rock salt. Also, the impact of long-term precipitation in the absence of rain sewerage in the subject area is reflected on the building of the Music School.

Keywords: precipitation, subsidence, salt mining, stormwater sewer. 